\title{
Towards effective communication between sports recreation specialists and intellectually disabled athletes: An exploratory study
}

\author{
Bassem Mohamed Tohamy \\ Associate professor, Faculty of Physical Education, Helwan University
}

The disabled people are getting recently more attention in sports field (Sack \& McLean, 1997). Governmental regulations regarding disabled people have provided several guidelines for individuals with disabilities related to both businesses and society which in turn directed concern to disabled people specifically from sports professionals (MacDonald, et al.,2016) Intellectual disability is one of the most significant health problems in Europe (Wilhelmsson, et al.,2010). Sharing in leisure activities, finding a suitable job, and living in an independent way as possible are basic objectives for people with intellectual disability (Elder \& Goosens, 1994; Sack and Mclean, 1997). However, Communication obstacles with individuals of intellectual disabilities are still common (Bott et al., 1997; Bradshaw, 2001). According to The UN Convention on the Rights of People with Disabilities, communication problems are regarded as one of the key barriers to interact effectively with this segment (Pinazo \& Reina, 2017)

The integration of individuals with disabilities has recently got more attention through inclusive programs in education, employment and various support programs which yielded groups who communicate with individuals with intellectual disability (Keith et al., 2015).

Moreover, there is an increasing attention provided in order to support communication between individuals with intellectual disability and people interacting with them (Mirenda \& Iacono, 1990). Professionals and service providers have to be aware of communication abilities of individuals with intellectual disability and adjust their communication performance in accordance (Bradshaw, 2001). In this concern, McConkey, et al., (1999a) indicated that communication of people working in disability field contributes to the challenging behaviors of this segment.

The emphasis of previous research that investigate the interaction between service providers and individuals with intellectual disability (Bakken, et al., 2008) was on the quality and quantity of communication, while less concern has been given to the relationship between staff who interact with this segment and their communication needs (Bradshaw, 2001).

Despite the efforts made to enhance communication with individuals with intellectual disability by improving careers' interactions (McConkey, et al., 1999a), there is a shortage of information concerning how sports recreation specialists communicate with athletes with intellectual disabilities. Sports recreation specialists are playing an important role in the success of intellectually disabled athletes' experience. Since communication problems are common among people with intellectual disability, sports recreation specialists who interact with this segment have to evaluate communication abilities of intellectually disabled people and adjust their communication attitudes accordingly (McConkey, et, al., 1999b; Schalick III et al,. 2012).

In this respect, Mirenda and Iacono, (1990) pointed out that gaining essential information regarding communication capabilities of individuals with intellectual disability people is important to specify communicating barriers with this segment. Moreover, shortage of this knowledge could make sports recreation specialists communicating with this segment unaware of the attempts done by intellectually disabled athletes to communicate.

Communication methods vary among intellectually disabled people; some may use speech, others depend greatly on non-verbal communication. Practices of professionals and service 
providers who communicate with them should be flexible (Keith et al., 2015; Sack \& McLean, 1997).

Previous studies has revealed that communication with individuals with intellectual disability is a challenging issue as there is a problem linked with receiving and understanding messages (Martin, et al., 2010; Schalick III, et al., 2012).

Previous research has shown as well that failure of service providers to adjust their communication styles to the communication capabilities of the people who have intellectual disability, for example not paying a much attention to non-verbal communication, is one of the basic problems in communicating with this segment (Wilhelmsson, et al., 2010; Sigafoos et al., 2016).

Therefore, enhancing communication competences of sports recreation specialists is considered a key challenge to succeed in interacting with athletes with intellectual disability. Lack of necessary information of different aspects and requirements of various disabilities and also lack of specific designed training for professionals and service providers are considered basic barriers for successful communication with individuals with intellectual disability (Hall, 2008; Pinazo \& Reina, 2017; Sack and McLean, 1997).

Hogg et al., (2001) pointed out in their study that individuals with profound intellectual and multiple disabilities (PIMDs) do not depend on verbal communication. Instead, they rely on, body language, vocal sounds, facial expressions and behavior to interact. Accordingly, it is important for staff who provide support to intellectually disabled individuals to have more knowledge regarding their communication methods and adjust their communication behavior accordingly.

\section{The role of sports recreation specialists}

Previous research has revealed that those who communicate with individuals with intellectual disability may face situations that could not be predicted and that identifying particular communication requirement, knowledge and strategies are substantial elements to overcome these situations and to achieve success in communication (Bradshaw, 2001; Pinazo \& Reina, 2017; Sack \& McLean, 1997).

Hall (2008) pointed out that one of the key obstacles in inclusion of disabled individuals is the "attitudinal barrier" and that training programs designed to increase awareness of disability of service providers who communicate with this segment has an important positive impact on employees' understanding of the individual's disability and the problems he/she is having will support the employees' information, attitude and performance in interacting with this segment.

Sports recreation specialists are one of those professionals who have a direct interact with athletes with intellectual disability (McDonald et al., 2016) and have to develop their information, attitude, and communication capabilities when contacting with this segment.

based on previous studies that confirm the effect of service providers' communication competences, attitude on the interaction success with individuals with intellectual disability and building on previous research which indicated the significance of using noncommunication ways among this segment, and also the positive impact of disability awareness training on improving service providers' information of intellectually disabled individuals' communication requirements, this study proposes the following hypotheses:

H1: non verbal communication methods are more suitable than verbal communication methods when contacting with intellectually disabled individuals

H2: Disability awareness training have a positive effect on raising sports recreation specialists' knowledge and understanding of intellectually disabled athletes' communication requirements.

Sport recreation specialists are playing a key role in the success of intellectually disabled experience. Therefore, sport recreation specialists should have the skills of interacting 
with others to communicate in a way that responds to the different needs of athletes because the performance of sport recreation specialists affects satisfaction of athletes with special needs.

Since communication skills of Sport recreation specialists are key determinants of the success of athlete's experience (MacDonald et al., 2016), the performance and efficiency of the sports recreation specialists can contribute significantly in enhancing the experience of the athlete and develop the skills of the intellectually disabled athletes

There is a paucity of studies that examine communication competences of sports recreation specialists when contacting intellectually disabled athletes despite the recognized important role played by sports recreation specialists in influencing athletes' experience. The current study investigates basic communication competences of sports recreation specialists communicating with intellectually disabled tourists.

There are three substantial areas in particular are worthy to examine. First, the potential contribution of sports recreation specialists' communications to enrich the experience of intellectually disabled athletes' experience which has not been investigated yet. Second, knowledge on how sports recreation specialists regard the significance of various verbal and non-verbal communication ways when contacting this segment. Third, the extent to which the training workshops can offer information on various intellectual disabilities' aspects and communication requirements support sports recreation specialists to choose the suitable communication attitude and adjust their performance to the various needs of this segment. The key objective of this study is to fill these three gaps.

It proposes a comprehensive model that includes sports recreation specialists' communication competencies (through verbal and non-verbal communication methods). Furthermore, it offers sports recreation specialists with necessary knowledge and awareness of particular communication requirements of intellectually disabled athletes. Therefore, improving sports recreation specialists' understanding of this significant segment.

\section{Importance of communication for athletes with intellectual disability}

Successful communication is an important dimension to achieve quality of life of individuals with intellectual disability (Martin, et al., 2010). Communication deficiencies are key problem of intellectually disabled individuals (Sigafoos et al., 2016). Previous research revealed that many individuals with intellectual disability face hard situations that yield frustration because of the inability to convey their emotions and needs (Pinazo \& Reina, 2017). Specifying various resources, strategies and knowledge regarding different communication requirements is a key issue to overcome these barriers (Pinazo \& Reina, 2017).

\section{Previous literature}

1. The study of (Hammond et al., 2014) titled "" Attitudes of Australian swimming coaches towards inclusion of swimmers with an intellectual disability: An exploratory analysis." The study Investigates attitudes of Australian swimming coaches towards inclusion of swimmers with intellectual disability. The study revealed that the Australian swimmers who have intellectual disability have problems concerning following instructions, remembering strategies and staying on task. Accordingly, coaches may interact with swimmers who do not follow instructions and those athletes may be ignored. However, attitudes of intellectually disabled athletes might be affected greatly and be guided by attitudes and performance of coaches as well as the communication methods of coaches when interacting with this 
segment. This study divided coaches into three groups (group 1: always communicate with intellectually disabled swimmers, group 2: sometimes communicate with intellectually disabled swimmers and group 3: never communicate with intellectually disabled swimmers). The study investigated differences among the three groups. It is revealed that the first group of coaches exhibit a positive attitude towards this segment compared to the third group of couches. They have also a positive believe and understanding of the abilities of those athletes compared to the second group of couches. This study recommends improve learning of coaches to meet the needs of this segment of athletes.

2. The study of (MacDonalds et al., 2016) titled "Understanding Sources of Knowledge for Coaches of Athletes with Intellectual Disabilities" their study aims to understand how coaches of intellectually disabled athletes acquire their knowledge. To achieve their objective, they carried out structured telephone interviews with fortyfive Special Olympics Canada coaches. They examined current and ideal sources of coaching information and knowledge. Knowledge of coaching were classified according to competition, organization and training. The findings of this study revealed that key learning method of coaches are through doing and through consultation of coaching peers. The study revealed as well that coaches consider structured coaching courses as ideal sources of coaching knowledge as well as from mentors and administrative support, and finally self learning and from their peers. The study recommends that education and training of coaches concerning intellectual disability should be considered.

3. The study of Sara H. Sack and Lee K. McLean (1997) titled "Training Communication Partners: The New Challenge for Communication Disorders Professionals Supporting Persons with Severe Disabilities”. In their study, they revealed that people who have profound disabilities are seeking to participate in leisure events and activities with the community; consequently, they want to communicate in an effective way with other individuals in their society. Without particular concern to environments and communications, people who do not use symbolic communication methods or who rely on non- speech symbolic systems have few opportunities to interact effectively and to convey communication messages correctly. The authors indicated that professionals have to pay much concern to develop communication-rich environments and on dealing with communication partners to confirm that they expect, understand, and respond to communication needs from people with profound disabilities. They pointed out that training courses should include professionals and should be designed to adapt to the specific needs of this segment. The authors suggest that future research should aim to assess the impact of training courses attended by professionals and modify the contents of these training courses accordingly to be more effective.

4. The study of (Hall, 2008) titled "Changing the way employees interact with guests with disabilities. This study aims to examine the effectiveness of a disability awareness workshop and its impact on theme park staff performance. The study posed two research questions, the first question is: would staff who attended a disability awareness workshop exhibit a better knowledge concerning disability matters? The second question is: would they adjust their attitudes toward disabled people? The participants of this study were 40 staff. The Facts About Disabilities Scale (FAD) and the Interaction With Disabled Persons Scale (IDP) were distributed among those employees as a pretest. Employees attended a one day disability awareness workshop. After the workshop, the FAD and the IDP scales were distributed among those employees as a posttest. Analysis of covariance indicated statistically 
significant differences in the employees' knowledge levels and exhibiting more positive attitudes toward disabled guests after attending the disability awareness workshop. The author proposed different recommendations for future research.

5. The study of (Bradshaw, 2001) titled "Complexity of staff communication and reported level of understanding skills in adults with intellectual disability". In this study the author displayed professionals' reports concerning their attitudes after interacting with 22 individuals with intellectual disability and then compared this with video observations of the communication behaviors used by employees with 12 of these service users. The researcher coded these interactions according to the communication method, the role of the act and the degree of complexity. The findings indicated that employees do not pay much concern to verbal communication and intensely use non-verbal communication methods. The results revealed as well that a mismatch between the reported degree of understanding of the service user and the degree of the complication of the language used. Employees were unable to adjust their communication methods to the actual skills of the service user and an average of $45 \%$ of communicative behaviors were outside the understanding skills of the person that were reported. The author discussed several and proposed different recommendations concerning professional behaviors in this concern.

\section{The research procedures}

Research methodology: the researcher used the descriptive methodology. Research sample: the researcher used a purposive sampling technique. The sample includes coaches who train athletes with intellectual disability during their attendance to a training course organized by Ministry of Youth and Sports. The questionnaires were distributed throughout 9 training sessions in four month from February 2018 to May 2018. The study sample consists of (115) coaches.

\section{Data collection}

The researcher designed a research questionnaire that consists of two dimensions with " 32 " items. The first dimension "verbal communication methods" involves " 16 " items and the second dimension "non-verbal communication methods" includes " 16 " items.

*The two dimensions have been presented to 5 specialists in the field of sports management in Faculty of Physical Education Helwan University and have been asked to do the following:

1- $\quad$ To determine if the items belong to the specified dimension?

2- $\quad$ to add of either verbal or non-verbal communication methods that were not included in the existing set of measures or delete items that are not relevant

Based on the review of the five specialists, some items were reworded for more clarity to the research sample. A five-point scale (strongly disagree-disagree-neutral-agree-strongly disagree) has been used in this concern.

Internal consistency reliability: Internal consistency reliability was measured by assessing correlation coefficient between the item and the total marks of its construct through applying the questionnaire on " 30 " individuals "the research sample" as revealed in the following results:

$$
\text { لم الحماحمي ، أ.د. عايدة عبد العزيز ، أ.د. بلال عبد العزيز ، أ.د. يحي الجيوشي ، أ. د. محمد سعيد . }
$$


Table (1) Correlation coefficient between the item and the total marks of its construct $(\mathrm{N}=30)$

\begin{tabular}{|c|c|c|c|c|c|c|c|}
\hline \multicolumn{4}{|c|}{ Verbal communication } & \multicolumn{4}{|c|}{ Non-verbal communication } \\
\hline items & $\begin{array}{c}\text { Corre } \\
\text { lation } \\
\mathrm{t}\end{array}$ & items & $\begin{array}{l}\text { Correl } \\
\text { ation }\end{array}$ & items & $\begin{array}{l}\text { Correlat } \\
\text { ion }\end{array}$ & items & $\begin{array}{c}\text { Correl } \\
\text { ation }\end{array}$ \\
\hline 1 & $\cdot, \varepsilon \leqslant r$ & 9 & $\cdot, 711$ & 1 & . OYA & 9 & $\cdot, \mathrm{rA \Lambda}$ \\
\hline 2 & $\cdot, r \wedge 9$ & 10 & $\cdot$, гт9 & 2 & $\cdot, \varepsilon 17$ & 10 & $\cdot$, , 0 Y \\
\hline 3 & $\cdot, 710$ & 11 & $\cdot, r v \varepsilon$ & 3 & $\cdot, r q \varepsilon$ & 11 & $\cdot, 7 \vee 9$ \\
\hline 4 & $\cdot, r v$. & 12 & $\cdot, r 90$ & 4 & $\cdot, 0 \cdot 1$ & 12 & $\cdot, r \wedge \varepsilon$ \\
\hline 5 & $\cdot, r q$. & 13 & $\cdot, 001$ & 5 & 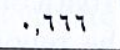 & 13 & $\cdot, 741$ \\
\hline 6 & $\cdot, 711$ & 14 & $\cdot,\{r \mid$ & 6 & $\cdot,\{r\}$ & 14 & $\cdot$, rar \\
\hline 7 & $\cdot, r q q$ & 15 & $\cdot .079$ & 7 & $\cdot, \mid q^{\prime}$ & 15 & $\cdot, \leqslant$ Or \\
\hline 8 & $\cdot, \Gamma \wedge \varepsilon$ & 16 & $\cdot, T 1 \mathrm{~V}$ & 8 & $\cdot, \varepsilon \cdot 1$ & 16 & $\cdot,\{\ldots$ \\
\hline
\end{tabular}

As indicated in table (1) all correlation coefficient between each item and the total marks of its construct were all statistically significant $(\mathrm{P}<0.05)$ which confirms the internal consistency reliability of all the " 32 " items

Reliability: the researcher assessed reliability through calculating Cronbach's alpha values for each dimension according to the equation of Kuder\& Richardson and modification of Cronbach as illustrated in table (2)

Table (3) Cronbach's alpha values for each dimension

\begin{tabular}{c|c|c}
\hline \hline & Dimension & Alpha values \\
\hline $1-$ & Verbal communication & $\cdot, 0 \mathrm{~T}$ \\
\hline $2-$ & Non-verbal communication & $\cdot, 01 \wedge$ \\
\hline$*(\mathrm{R}=.361, \mathrm{df}=28, p<0.05)$ &
\end{tabular}

According to table (2), alpha values range from $\cdot, 01 \mathrm{~V}$ to, 0 , r 1 for all dimensions of the questionnaire items which verify items reliability.

\section{Field study}

The pre-test was used as a procedure to assess the trainees' awareness and knowledge level concerning communication with intellectually disabled athletes and the most important items according to their perception before and after the workshop which the researcher organized. The questionnaires were distributed among trainees and participation was on a voluntary

basis.

The researcher pointed out study objectives and importance to the participants before distributing the questionnaires. After collecting the completed questionnaires, a short workshop has been conducted to the trainees to provide them with important information regarding individuals with intellectual disability, types of intellectual disability, and various communication ways with this segment. Moreover, the researcher displayed a video of coaches interacting with athletes with intellectual disability. The duration of each workshop was 2 hours. A post-test questionnaire with the same items of verbal and non-verbal communication methods was distributed immediately after the workshop to evaluate whether participants who attended the disability awareness workshop would exhibit a greater knowledge in disability issues and communication methods after attending the workshop. The post-test questionnaires were collected after being completed. 


\section{Results}

Table (3) Differences in participants' perception of verbal and non-verbal communication before and after workshop

\begin{tabular}{|c|c|c|c|}
\hline Items & Before workshop & Before workshop & Sig. \\
\hline \multicolumn{4}{|l|}{ Verbal communication } \\
\hline Using speech & 4.6 & 4.9 & 0.000 \\
\hline Using repeated phrases & 4.1 & 4.6 & 0.000 \\
\hline $\begin{array}{l}\text { Using open questions (Ask } \\
\text { athletes questions rather than } \\
\text { always providing directions) }\end{array}$ & 3.5 & 3.9 & 0.004 \\
\hline Using clarification & 4.3 & 4.5 & 0.000 \\
\hline Using positive language & 4.2 & 4.5 & 0.000 \\
\hline $\begin{array}{l}\text { Using reinforcements (verbally } \\
\text { reinforce the athlete immediately } \\
\text { after a desired action, make the } \\
\text { reinforcement action-oriented } \\
\text { and specific to the skill). }\end{array}$ & 4.3 & 4.6 & 0.000 \\
\hline Using request to repeat & 4.1 & 4.4 & 0.000 \\
\hline $\begin{array}{c}\text { Talks (the coach talks slowly, } \\
\text { clearly, loudly) }\end{array}$ & 4.6 & 4.9 & 0.000 \\
\hline $\begin{array}{l}\text { Opinions (encourage athletes to } \\
\text { talk and express their opinions, } \\
\text { encourage athletes to think for } \\
\text { themselves. }\end{array}$ & 4.3 & 4.5 & 0.061 \\
\hline Suggestions & 3.7 & 4.1 & 0.000 \\
\hline $\begin{array}{c}\text { Using short sentences (Do not use } \\
\text { long sentences or multi-part } \\
\text { instructions). }\end{array}$ & 4.2 & 4.5 & 0.000 \\
\hline $\begin{array}{l}\text { Using active rather than passive } \\
\text { verbs }\end{array}$ & 4.00 & 4.4 & 0.000 \\
\hline Using suitable grammar & 4.3 & 4.6 & 0.000 \\
\hline Using practical examples & 4.2 & 4.7 & 0.000 \\
\hline $\begin{array}{l}\text { Presenting ideas in a clear } \\
\text { way }\end{array}$ & 4.4 & 4.7 & 0.000 \\
\hline $\begin{array}{l}\text { Using clear easy language (Use } \\
\text { words that an athlete can } \\
\text { understand for example "see the } \\
\text { ball" as opposed to "find the } \\
\text { target." }\end{array}$ & 4.6 & 4.7 & 0.575 \\
\hline \multicolumn{4}{|l|}{ Non-verbal communication } \\
\hline Facial expressions & 4.1 & 4.4 & 0.000 \\
\hline $\begin{array}{l}\text { Using gestures (for example using } \\
\text { thumbs up and high five) }\end{array}$ & 4.2 & 4.6 & 0.000 \\
\hline Using body language & 4.3 & 4.6 & 0.000 \\
\hline Using sign language & 4.1 & 4.6 & 0.000 \\
\hline Using enlarged pictures & 3.8 & 4.7 & 0.000 \\
\hline $\begin{array}{l}\text { Pointing to symbols/objects } \\
\text { (pointing to pictures) }\end{array}$ & 3.8 & 4.3 & 0.000 \\
\hline Using vocalizations & 3.9 & 4.5 & 0.000 \\
\hline
\end{tabular}




\begin{tabular}{|c|c|c|c|}
\hline $\begin{array}{c}\text { Using body movements coach- } \\
\text { demonstrated physical } \\
\text { movements that remind athletes } \\
\text { of the correct way to perform a } \\
\text { skill }\end{array}$ & 4.0 & 4.5 & 0.000 \\
\hline $\begin{array}{c}\text { )eye contact (Eye gaze Using } \\
\begin{array}{c}\text { Touch cues: taps on the athletes' } \\
\text { body to elicit movement. Be sure } \\
\text { the athlete is comfortable being } \\
\text { touched before using touch cues }\end{array}\end{array} \quad 4.1$ & 4.9 & 0.001 \\
\hline Using head nods & 4.2 & 4.6 & 0.000 \\
\hline $\begin{array}{c}\text { make sure an athlete is (Looking } \\
\text { looking at you and can hear you } \\
\text { when making a coaching point. } \\
\text { When needed, physically prompt } \\
\text { an athlete to look at you.) }\end{array}$ & 4.0 & 4.6 & 0.000 \\
\hline Using objects that can be touched & 4.0 & 4.5 & 0.000 \\
\hline Smiling & 4.2 & 4.6 & 0.000 \\
\hline Laughing & 4.6 & 4.5 & 0.000 \\
\hline Listening & 4.3 & 4.7 & 0.327 \\
\hline $\begin{array}{c}\text { Keeping appropriate distance } \\
\text { between coach and the athlete) }\end{array}$ & & 4.7 & 0.000 \\
\hline
\end{tabular}

\section{Discussion}

Building on previous research in communication with individuals with intellectual disabilities (Bakken, et al., 2008; Bradshaw, 2001; Hall, 2008), the current study is considered an extension to the existing literature by examining communication competences of sports recreation specialists interacting with athletes with intellectual disability. Furthermore, the current study provides a model involving the verbal and non-verbal communication dimensions in assessing sports recreation specialists' communication competences contacting intellectual disabled athletes. This study investigates the relative importance of non-verbal communication methods compared to verbal communication methods according to sports recreation specialists' point of view. Moreover, the study examines the differences between the pre-test and post-test workshop point of view to evaluate the potential effect on improving the knowledge and awareness of sports recreation specialists regarding the disabled athletes and its characteristics and communication needs.

The study findings revealed that the non-verbal communication dimension is more important than the verbal communication. This is consistent with the findings of Martin, et al., study (2010) that individuals with intellectual disability depend on non-verbal communication. Similarly, results of Mirenda and Iacono study (1990) indicated that although individuals with intellectual disability use both verbal and non-verbal communication, non-verbal communication is the most observed among individuals with intellectual disability.

Accordingly, being aware of the athlete's disability type and communication capabilities are very important for sports recreation specialists' success. In this concern, recent studies have revealed that the lack of knowledge of various disabilities and primary requirements and the lack of specialized professional training who communicate with intellectually disabled individuals have a negative effect (Pinazo et al., 2017).

Results also revealed that sports recreation specialists have higher mean scores compared to their scores before disability awareness workshop for verbal communication and non-verbal communication methods with athletes with intellectual disability. These results confirm the hypothesis that the higher the level of training on various communication needs of 
intellectually disabled individuals, the higher the level of information, awareness and performance.

Therefore, specialized training is an important matter for sports recreation specialists to improve their performance and communication skills. Accordingly, the study suggest designing specialized training courses and workshops to sports recreation specialists to increase their awareness and knowledge regarding disabled athletes specifically athletes with intellectual disability to identify the specific needs of this segment.

\section{Conclusion}

Although communication is regarded as an important approach to investigate the determinants of the satisfaction of athletes with special needs, there is a paucity of research that examine communication competences of sports recreation specialists when interacting with intellectually disabled athletes. The study concludes that communication competences of sports recreation specialists contribute significantly in enriching the experience of intellectually disabled athletes and satisfaction specifically the non-verbal communication dimension because of its effect on the communication success

This study extends previous research by proposing a model that investigates sports recreation specialists' basic communication skills when communicating with athletes with intellectual disability. The study provides a framework that sets sports recreation specialists' point of view concerning verbal and non-verbal communication when interacting with intellectually disabled athletes thereby moved beyond prior research on athletes with intellectual disabilities.

The study recommends as well that the sports recreation specialists have to assess communication abilities of athletes with intellectual disability to satisfy this segment and achieve their quality of life.

The study provides the representative dimensions of sports recreation specialists' communication competences who interact with athletes with intellectual disability and the relevant indicators that measure each dimension. Dimensions and indicators were validated by specialists in sports management. Therefore, sports recreation specialists can evaluate their performance, athletes' satisfaction, the quality of particular services offered to athletes with special needs and the necessary improvements that should take place.

The main objective of this study is to raise awareness of the specific needs of athletes with intellectual disability and improve communication competences of sports recreation specialists who interact with this segment.

The study recommends as well the importance of organizing training courses that respond to the special needs of athletes with intellectual disability for example official sports authorities that organize regular training courses to sports recreation specialists and also faculties that have sports recreation departments to provide students with subjects that raise their knowledge and awareness of intellectually disabled athletes which aims to guarantee the optimal communication between two parties: the sports recreation specialists and athletes with intellectual disabilities

In sum, the current study makes several contributions to both sports and disability research; the study contributes to the sports field by proposing ways which sports recreation specialists can use to enhance their communication competences when interacting with athletes with intellectual disability. It contributes as well to disability field through examining ways of improving their athletes' experience and improving their quality of life. 


\section{References}

1- Bakken,T.L.,Eilertsen,D.E.,Smeby,N.A.andMartinsen,H.(2008)“Observingcom munication skills in staff interacting with adults suffering from intellectual disability, autism and schizophrenia", VARD I NORDEN. PUBL. NO. 87, VOL. 28, NO. 1, pp.30-35

2- Bott C., Farmer R. \& Rohde J. (1997) "Behaviour problems associated with lack of speech in people with disabilities" Journal of Intellectual Disability Research, Vol. 41, pp.3-7.

3- Bradshaw, J. (2001) "Complexity of staff communication and reported level of understanding skills in adults with intellectual disability" Journal of Intellectual Disability Research, Vol. 45, No. 3, pp. 233-243

4- Elder, P., \&Goosens, C. (1994) "Engineering training environments for interactive augmentative communication: Strategies for adolescents and adults who are moderately/ severely developmentally delayed" Birmingham, AL: Southeast Augmentative Communication Conference Publications.

5- Hall, E. W. (2008) "Changing the way employees interact with guests with disabilities" Journal of Disability Policy Studies ,Vol. 19 No. 1, pp.15-23

6- Hammond, A. M., Young, J. A., \&Konjarski, L. (2014). Attitudes of Australian swimming coaches towardsinclusion of swimmers with an intellectual disability: An exploratory analysis. International Journal of Sports Science \& Coaching, 9, 1425-1436.

7- Hogg,J.,Reeves,D.,Roberts,J.andMudford,O.C.(2001)“Consistency,contextandc onfidence in judgments of affective communication in adults with profound intellectual andmultiple disabilities" Journal of Intellectual Disability Research, Vol.45, No. 1, pp.18-29

8- Keith J. M. , Bennetto, L. and Rogge, R. D. (2015) "The relationship between contact and attitudes: Reducing prejudice toward individuals with intellectual and developmental disabilities" Research in Developmental Disabilities, Vol. 47, pp. 14-26

9- McConkey,R.,Morris,I.andPurcell,M.(1999a)“Communicationsbetweenstaffand adultswith intellectual disabilities in naturally occurring settings" Journal of Intellectual Disability Research, Vol.43, No. 3, pp 194-205

10-McConkey, R., Purcell, M., and Morris, I. (1999b) "Staff perceptions of communication with a partner who is intellectually disabled" Journal of Applied Research in Intellectual Disabilities, Vol. 12, No 3, pp. 204-210

11-MacDonald, D. J., Beck, K., Erickson, K., \&Côté, J. (201 ฯ). Understanding sources of knowledge forcoaches of athletes with intellectual disabilities. Journal of Applied Research in Intellectual Disabilities, 29(3):242-r $\leqslant 9$

12-Martin, A. M., O’ Connor - Fenelon, M., and Lyons, R. (2010) "Non-verbal communication

betweennursesandpeoplewithanintellectualdisability:areviewoftheliterature" Jou rnal of Intellectual Disabilities, Vol. 14 No. 4, pp.303-314 
13-Martin, G. E., Losh, M., Estigarribia, B., Sideris, J., and Roberts, J. (2013) "Longitudinal profiles of expressive vocabulary, syntax and pragmatic language in boys with fragile X syndrome or Down syndrome" International Journal of Language and Communication Disorders, Vol. 48, pp. 432-443.

14-Mirenda,P.andIacono,T.(1990)"Communicationoptionsforpersonswithseverean dprofound disabilities: State of the art and future directions" JASH, Vol. 15, No. 1, pp.3-21

15-Pinazo, E.P. \& Reina, M.C. (2017) "A model to enhance interaction for people with severe intellectual disability in healthcare, education and interpreting, 7th International Conference on Intercultural Education "Education, Health and ICT for a Transcultural World”, EDUHEM 2016, 15-17 June 2016, Almeria, Spain Procedia - Social and Behavioral Sciences Vol. 237, pp. 1189 - 1195

16-Sack, S.H. and McLean, L.K. (1997) "Training communication partners: the new challenge for communication disorders professionals supporting persons with severe disabilities" Focus on Autism And Other Developmental Disabilities, Vol. 12, No. 3, pp. 151-158

17-Schalick III, W. O., Westbrook, C. and Young, B. (2012) "Communication with individuals with intellectual disabilities and psychiatric disabilities: A summary of the literature, working paper WP 2012-264, Michigan Retirement Research Center University of Michigan

18-Sigafoos , J., Lancioni, G. E., O’Reilly, M. F., Lang, R., Singh, N.N., Didden, R., Green, V. A., and Marschik, P. B. (2016) "Communication" In Singh, N.N. (eds.) "Handbook of Evidence-Based practices in intellectual and developmental disabilities" Springer International Publishing Switzerland.

19-Wilhelmsson,A.B.,Graneheim,U.H.,Berge,B.M.,Johansson,S.,Åström,S.(2010)“ Everyday life experiences among relatives of persons with mental disabilities", Procedia Social and Behavioral Sciences Vol. 2, pp.4896-4900 